\title{
UNIVERSITETO STUDENTŲ GYVENSENOS YPATUMAI PANDEMIJOS METU: DARBO KOMPIUTERIU APLINKA IR FIZINIS AKTYVUMAS
}

\author{
Vaiva Strukčinskaitė ${ }^{1}$, Birutė Strukčinskienè ${ }^{\mathbf{2}}$, Neringa Strazdienè ${ }^{\mathbf{2}}$, Sigitas Griškonis ${ }^{\mathbf{2}, 3}$ \\ ${ }^{1}$ Vilniaus kolegija, ${ }^{2}$ Klaipédos universitetas, ${ }^{3}$ Klaipédos universitetinè ligonine
}

Raktažodžiai: universiteto studentai, gyvensena, pandemija, darbas kompiuteriu, fizinis aktyvumas.

\section{Santrauka}

COVID-19 pandemijos metu perèjimas prie nuotolinio mokymo(si) pakeitè universiteto studentų studijų aplinką ir veiklos pobūdį, pailgèjo darbo kompiuteriu laikas. Tuo laikotarpiu didejo jaunų žmonių fizinis pasyvumas ir sèdimos veiklos trukmè.

Darbo tikslas - tirti universiteto studentų gyvenseną, darbo kompiuteriu aplinką ir fizinio aktyvumo ypatumus pandemijos metu. Tyrimas atliktas 2020 m., Lietuvos aukštosiose universitetinèse mokyklose, po pirmosios pandemijos bangos. Apklausoje dalyvavo 201 studentas: 98 vaikinai $(48,8 \%)$ ir 103 merginos $(51,2 \%)$. Taikytas Chi kvadrato $\left(\chi^{2}\right)$ testas. Duomenys laikyti statistiškai reikšmingais, kai $p \leq 0,05$. Tyrimas atskleide, kad 50,2\% visų tirtų jaunų žmonių prie kompiuterio praleido 6-10 valandu per dieną, $35,8 \%-3-5$ valandas per dieną ir $11,9 \%$ - daugiau kaip 10 valandų per dieną. Per parą kompiuteriu panašų laiko kiekị dirbo ir vaikinai, ir merginos. $68,7 \%$ studentų naudojosi nepatogiomis kèdèmis, $68,2 \%$ - skundèsi nepakankamu kompiuterinio stalo plotu, $65,7 \%$ - nepakankama darbo erdve. $22,9 \%$ respondentų naudojo kompiuterị esant labai geram apšvietimui, 55,2\% - esant geram, 21,4\% - esant vidutiniam apšvietimui. Dirbantys kompiuteriu studentai patyre trukdymus: 40,8\% respondentų trukdè kiti žmonès, 21,4\% - triukšmas, 37,8\% - buvo trukdomi dèl kitų priežasčių. Daugiau negu pusė apklaustųjų patyre kaklo, pečių ir nugaros srities skausmus. 10,9\% studentų savo fizinę sveikatą vertino kaip labai gerą, 49,3\% - gerą, 33,8\% vidutinę ir $6 \%$ - blogą. Tik 32,8\% studentu teigè, kad turi pakankamai žinių apie fizinès veiklos poveikị sveikatai. Nedidele dalis tirtų studentų (11,9 proc.) nurodé, kad jie mankštinosi ar sportavo bent 30 minučių kasdien, o
24,9 proc. - mankštinosi bent 30 minučiu 2-3 kartus per savaitę, 23,4 proc. -1 kartą per savaitę. 62,2 proc. jaunų žmonių sutiko, kad jie turètų būti fiziškai aktyvesni. 37,8 proc. jaunų žmonių dirbdami kompiuteriu reguliariai darè pertraukas. 68 proc. studentų mieliau sportuotų kartu su bendraamžiais ir draugais, o 19 proc. - su šeimos nariais. Išvados. Pandemijos metu dauguma studentų prie kompiuterio praleido daug valandų per dieną ir tik mažuma darè reguliarias pertraukas. Tirti jaunuoliai minejjo netinkamą darbo įrangą ir darbo aplinką, dauguma kentè ìvairių kūno vietų skausmus, nurodè, kad deda per mažai pastangų fiziniam aktyvumui ir fizinei veiklai didinti. Dauguma studentų norètų mankštintis su bendraamžiais ir draugais. Tyrimo rezultatai parodè studentų sveikos gyvensenos ugdymo, saugios ir sveikos darbo kompiuteriu aplinkos kūrimo ir fizinio aktyvumo skatinimo poreiki. Studentų informavimas apie fizinio aktyvumo poveiki sveikatai, jų motyvavimas būti fiziškai aktyvesniems ir patrauklesnès bei prieinamesnès fizinès veiklos organizavimas yra svarbūs veiksniai studentų sveikatai stiprinti.

\section{İvadas}

Judejjimas - svarbus jauno žmogaus sveikatos veiksnys. Mažas fizinis aktyvumas didina kraujagyslių, kvejpavimo, raumenų ir kaulų sistemų, diabeto, vėžio riziką ir mirtingumą [1-6]. Fizinis aktyvumas stiprina sveikatą, ugdo veiklų, judrų žmogų, skatina saviraišką, o fizinis pasyvumas, „ikalinimas“ kambaryje, kūno mankštos stoka kelia sveikatos problemų [7]. Vaikų ir jaunų žmonių gyvenseną sąlygoja ịvairūs veiksniai (amžius, pomėgiai, nuostatos, ịpročiai ir kt.), tačiau didelę itaką fiziniam aktyvumui daro šeimos gyvensena ir aplinka. Vaikams ir paaugliams augant, šie veiksniai kinta, mažèja tèvu itaka, o judrią veiklą vis labiau ima keisti sėdima veikla [8-10]. Fizinio aktyvumo ipročiai mokymosi mokykloje metais gali turèti įtakos jaunuolių gyvensenai studijų metais. 
Studijų universitete laikotarpiu keičiasi jaunuoliu gyvensena - aktyvi protinè veikla ir darbas su informacinemis technologijomis skatina vis daugiau laiko praleisti pasyviai. Moksliniai tyrimai parode, kad studijuojantys jauni žmonès daug laiko sėdi, daug valandų dirba kompiuteriu, mažai juda. Fizinis pasyvumas labiau pastebimas merginų grupejje, nei vaikinų [11-14]. Reguliarus studentų fizinis aktyvumas susijęs su daugeliu aplinkos veiksnių. COVID-19 pandemijos metu perèjus prie nuotolinio mokymo(si), keitėsi universiteto studentų studijų aplinka ir veiklos pobūdis, ilgejjo darbo kompiuteriu laikas. Naujausi tyrimai parodè, jog šiuo laikotarpiu didèjo jaunų žmonių fizinis pasyvumas, su maistu gaunamas energijos kiekis ir sėdimos veiklos trukmé $[15,16]$. Ilgai dirbant kompiuteriu, esant pasyviai raumenų veiklai, atsiranda atraminio judamojo aparato susirgimų. Mažas judejjimo aktyvumas, netinkama darbo poza, netinkamas įrangos išdèstymas, nesveika darbo aplinka turi įtakos ịvairių organizmo sistemų susirgimams [6]. Y.Wang ir kt. (2011) nustate, kad ilgalaikis darbas kompiuteriu susijęs su kaklo, pečių juostos, nugaros, viršutinių galūnių raumenų skausmais, kai sutrinka raumenų, sausgyslių, raiščių veikla dèl hipodinamijos [17]. Ilgai dirbant prie kompiuterio, ilgai sėdima viena

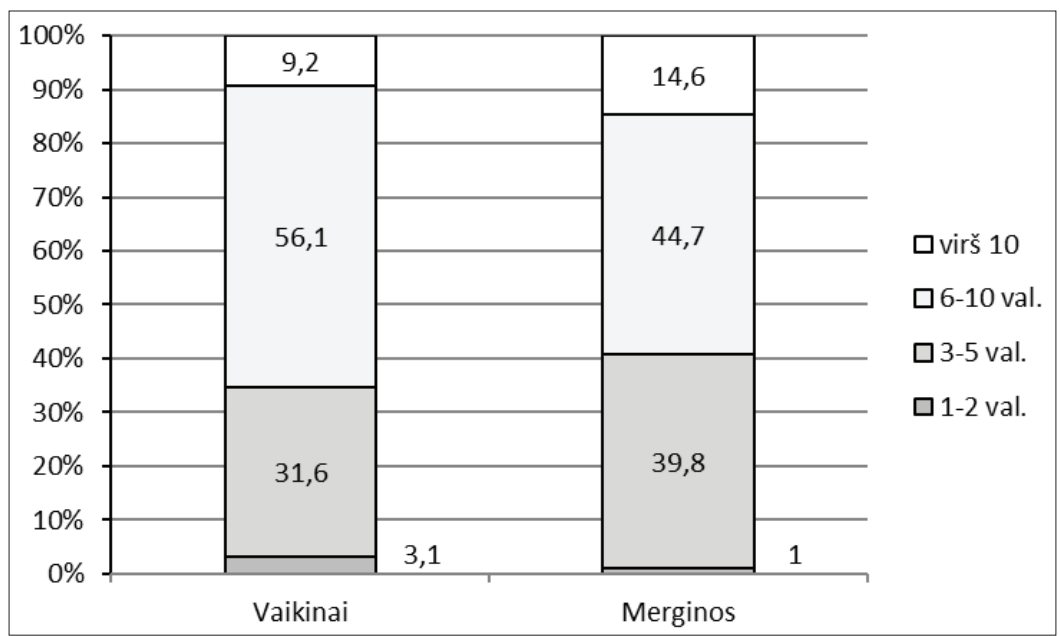

1 pav. Studentų prie kompiuterio praleistas laikas (val./parą) $\chi^{2}=4,569 ; l l s=3 ; p=0,206$

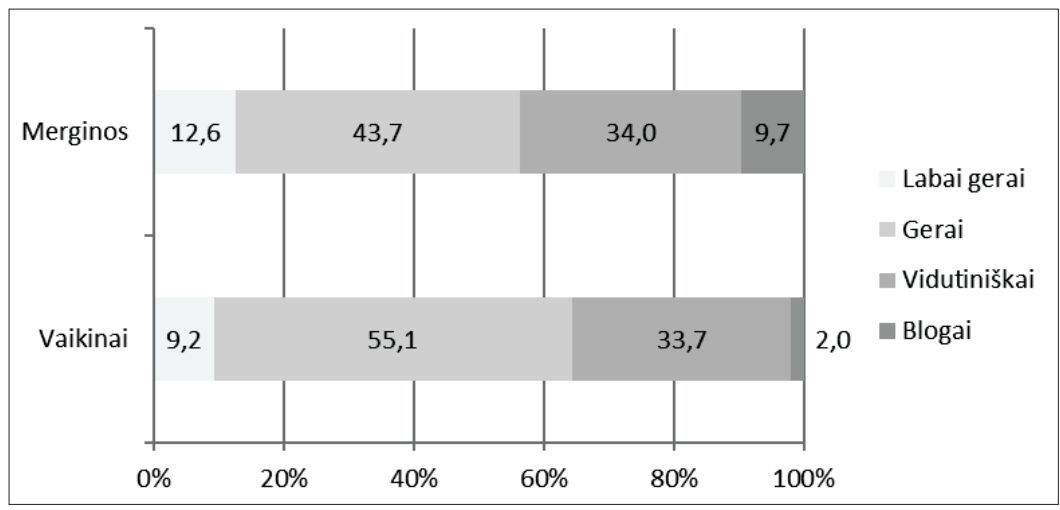

2 pav. Studentų fizinès sveikatos ịsivertinimas $\chi^{2}=6,817 ; l l s=3 ; p=0,078$ nejudama poza. Dèl tokio ilgalaikio sèdèjimo prasideda raumenų skausmai, kinta natūralūs stuburo linkiai, pertempiami ir varginami nugaros raumenys susilpnèja. Ilgą laiką sẻdėdamas žmogus pavargsta greičiau, nei dirbdamas judrų darbą [6].

Studentų gyvensenos tyrimai leidžia nustatyti jų gyvensenos ypatumus, atskleisti su fiziniu aktyvumu susijusius aspektus ir ivertinti darbo kompiuteriu aplinką. Siekiant vengti ilgai trunkančios sédimos pasyvios veiklos, svarbu kurti studentu fiziniam aktyvumui palankias gyvensenos ir studijų sąlygas, skatinti palankias fizinio aktyvumo nuostatas, mokyti racionaliai tvarkyti savo dienotvarkę.

Darbo tikslas - tirti universiteto studentų gyvenseną, darbo kompiuteriu aplinką ir fizinio aktyvumo ypatumus pandemijos metu.

\section{Tyrimo medžiaga ir metodai}

Tyrimas atliktas Lietuvos aukštosiose universitetinėse mokyklose 2020 metais, po pirmosios pandemijos bangos. Tyrimas kiekybinis, taikyta apklausa raštu. Klausimyną sudaré sociodemografine dalis ir klausimai apie studentų kompiuterinio darbo aplinką, fizinio aktyvumo ypatumus, fizinès sveikatos būklę. Apklausoje dalyvavo 201 studentas: 98 vaikinai $(48,8 \%)$ ir 103 merginos $(51,2 \%)$. Duomenys apdoroti SPSS programine iranga (25.0 versija). Taikytas Chi kvadrato $\left(\chi^{2}\right)$ testas. Duomenys laikyti statistiškai reikšmingais, kai $\mathrm{p} \leq 0,05$.

\section{Rezultatai ir jų aptarimas}

Tyrimo metu buvo klausiama, kiek laiko per parą studentai praleidžia prie kompiuterio. Tyrimo rezultatai parodè, kad iš 201(100 proc.) tiriamojo, pusè 101(50,2 proc.) prie kompiuterio praleido 6-10 valandų per dieną, trečdalis $72(35,8$ proc.) - 3-5 valandas per dieną ir 24 (11,9 proc.) - daugiau kaip 10 valandų per dieną. 55(56,1 proc.) vaikinai kompiuteriu dirbo 6-10 val., 31 (31,6 proc.) - 3-5 val., 9 (9,2 proc.) - daugiau negu 10 valandų. Merginų grupeje - 46 (44,7 proc.) prie 
kompiuterio praleido 6-10 val. per dieną, 41 (39,8 proc.) 3-5 valandas ir 15 (14,6 proc.) - daugiau kaip 10 valandu per parą. Vaikinai ir merginos prie kompiuterio per parą praleido panašiai ilgas darbo ar laisvalaikio valandas. Statistiškai reikšmingų skirtumų tarp vaikinų ir merginų pagal ši požymį nenustatyta $\left(\chi^{2}=4,569 ; 11 \mathrm{~s}=3 ; \mathrm{p}\right.$ $=0,206)$ (1 pav.).

Tyrimo metu analizuota studentų darbo kompiuteriu aplinka. Nustatyta, kad 138 (68,7 proc.) neturi patogios darbo kèdès, 137 (68,2 proc.) nepakankamas darbo stalo plotas, $132(65,7$ proc.) nepakanka darbo erdvès. 46(22,9 proc.) respondentai nurodè, kad jų darbo kompiuteriu vieta apšviesta labai gerai, 111(55,2\%) - naudojosi kompiuteriu esant geram apšvietimui, 43(21,4\%) -esant vidutiniam, o 1(0,5 proc.) - esant blogam apšvietimui.

Studentai teigè, kad dirbdami kompiuteriu patyrè trukdymus, todèl jiems buvo sunku susikaupti. 82(40,8\%) respondentai nurodè, kad jiems susikaupti ir dirbti kompiuteriu trukdè pašaliniai asmenys. 43(21,4\%) studentų darbui kompiuteriu trukdè triukšmas, o $76(37,8 \%)$ nurode kitas priežastis.

Daug laiko prie kompiuterio praleidžiantys studentai jautè įvairių kūno vietų skausmus. Apklausos rezultatai atskleide, kad daugiau negu pusė apklaustujų jautė kaklo ( 60,2 proc.), pečių ( 65,2 proc.) ir nugaros $(77,1$ proc.) srities skausmus.

Tyrimo metu studentų buvo klausiama, kaip jie ịvertintų savo fizinès sveikatos būklę. $22(10,9$ proc.) tiriamieji savo fizinę sveikatą vertino labai gerai, 99(49,3 proc.) - gerai, 68 (33,8 proc.) - vidutiniškai ir 12 (6 proc.) - blogai. Vaikinų pogrupyje: 9 $(9,2$ proc.) studentai nurodè, kad jų fizinè sveikata labai gera, $54(55,1$ proc.) - gera ir 33(33,7 proc.) - vidutinè. Merginu pogrupyje: 13 (12,6 proc.) studenčių fizinè sveikata labai gera, $45(43,7$ proc.) - gera, o 35(34 proc.) - vidutinè. Statistiškai reikšmingų skirtumų tarp lyčių pagal ši požymi nenustatyta $\left(\chi^{2}=6,817 ; 11 \mathrm{~s}=3 ; \mathrm{p}=0,078\right)$ (2 pav.).

Tik 66(32,8 proc.) apklaustieji teigè tu- rintys pakankamai žinių apie fizinès veiklos poveikị sveikatai, 51(25,4 proc.) nurodè, kad pakankamai žinių neturi, o 84(41,8 proc.) atsakè, kad nežino. $34(34,7$ proc.) vaikinai ir 17(16,5 proc.) merginų atsakè, kad neturi pakankamai žinių apie fizinio aktyvumo svarbą sveikatai, $28(28,6$ proc.) vaikinai ir 38 (36,9 proc.) merginos subjektyviai nurodè, kad turi pakankamai žinių apie fizinès veiklos poveiki sveikatai. Tyrimas atskleidè, kad statistiškai reikšmingai daugiau merginų, negu vaikinų mano turinčios pakankamai žinių apie fizinio aktyvumo svarbą asmens sveikatai $\left(\chi^{2}=8,777 ; 11 \mathrm{~s}=2 ; \mathrm{p}\right.$ $=0,012)(3$ pav. $)$.

Tyrimo metu analizuota, kaip dažnai jaunuoliai yra fiziškai aktyvūs ir užsiima fizine veikla bent 30 minučių per dieną. Apklausa atskleidè, kad nedidelè dalis tiriamuju - 24(11,9\%) bent 30 minučiu kasdien mankštinosi ar sportavo. $50(24,9$ proc.) mankštinosi bent 30 minučiu $2-3$ kartus per savaitę, $47(23,4$

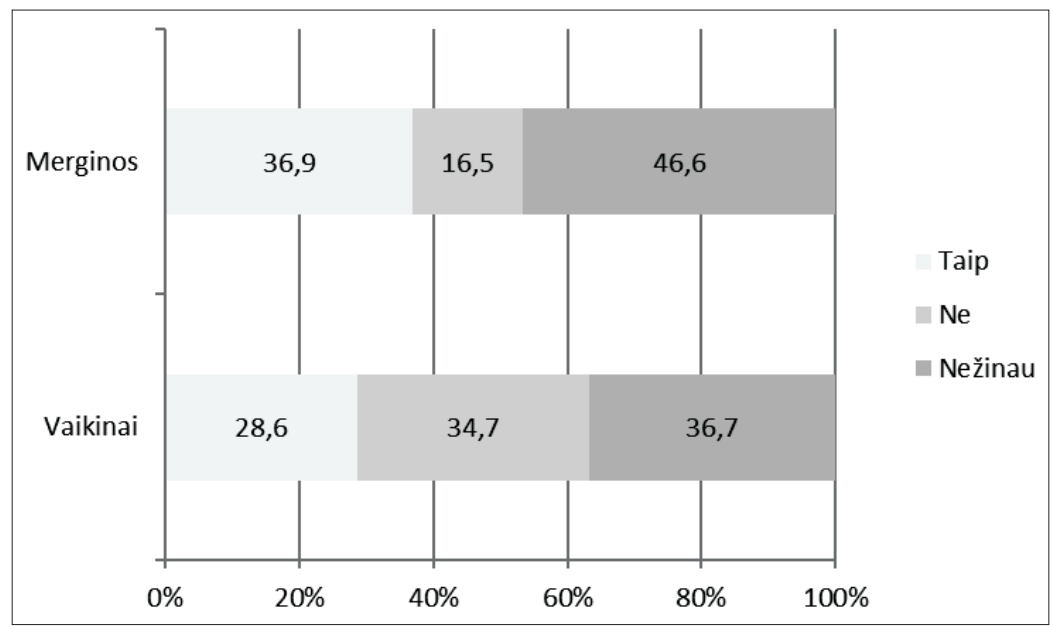

3 pav. Studentų žinių apie fizinio aktyvumo svarbą sveikatai ịsivertinimas $\chi^{2}=8,777 ; l l s=2 ; p=0,012$

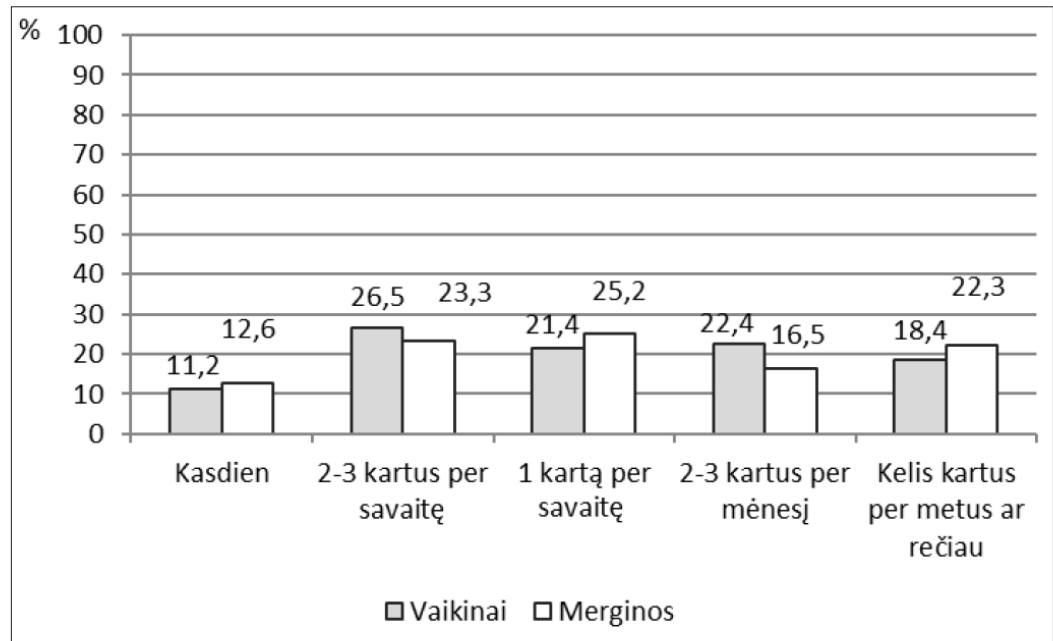

4 pav. Studentų fizinès veiklos, ne trumpesnès kaip 30 minučių per dieną, dažnis $\chi^{2}=1,906 ; l l s=4 ; p=0,753$ 
proc.) - 1 kartą per savaitę. 39(19,4 proc.) mankštinosi arba sportavo tik 2-3 kartus per mènesį, o 41(20,4 proc.) - tik kelis kartus per metus ar rečiau. Vaikinų pogrupyje fiziškai aktyvūs ne mažiau kaip 30 minučių per parą buvo 11(11,2 proc.), o 2-3 kartus per savaitę - 26 (26,5 proc.) tiriamieji. Merginų pogrupyje fiziškai aktyvios bent 30 minučių kiekvieną dieną buvo 13 (12,6 proc.), o 2-3 kartus per savaitę -24 ( 23,3 proc.) studentess. Statistiškai reikšmingų skirtumų tarp lyčiu pagal ši požymį nenustatyta $\left(\chi^{2}=1,906 ; 11 \mathrm{~s}=4\right.$; $\mathrm{p}=0,753)(4$ pav. $)$.

Tyrimo metu buvo klausiama, kaip studentams atrodo, ar jie turètų būti fiziškai aktyvesni, negu yra dabar. 125 (62,2 proc.) atsakè, kad reikètų būti fiziškai aktyvesniems, negu jie yra.

Prašomi nurodyti, ar naudodamiesi kompiuteriu dare reguliarias poilsio pertraukas, $i$ klausimą teigiamai atsaké 76(37,8 proc.) apklausos dalyviai.

I klausimą su kokiais žmonėmis jie mieliau, noriau sportuotų ar mankštintųsi, 125(68,2 proc.) studentai atsakè, kad norètų sportuoti kartu su bendraamžiais ir draugais, o 38(19 proc.) mieliau mankštintųsi ir sportuotų su šeimos nariais.

Tyrimo metu paaiškejjo, kad jauni žmonès, studijuodami nuotoliniu būdu, daug laiko praleido prie kompiuterio. Daugumos darbo kompiuteriu aplinka buvo netinkama. Studentai mažai mankštinosi ir sportavo, jų gyvensena buvo pasyvi, todèl nukentèjo sveikata (jaute ịvairų raumenų skausmus) ir gyvenimo kokybė. D. Dunstan ir kt. (2012) pabrèžia, jog asmenų, sédinčių 4 ir daugiau valandų per dieną, negalavimų rizika padidèja 80 procentų [1]. Mūsų tyrimas atskleidè, kad daugiau nei pusė tiriamujų per daug valandų praleido prie kompiuterio, sukeldami riziką savo sveikatai. L. Gallo ir kt. (2020) pastebejjo, kad dèl COVID-19 pandemijos taikytų fizinès izoliacijos priemonių, daugelyje pasaulio šalių, tarp jų ir Australijoje, universiteto studentų (merginų ir vaikinų) fizinis aktyvumas sumažèjo. Tai atskleidè neigiamą izoliacijos poveikį sveikatai [16]. Nepandeminiu laikotarpiu atliktas S. Lipošek ir kt. (2018) tyrimas parodè, jog dauguma $(79,8$ proc.) studentų buvo nepakankamai fiziškai aktyvūs [18]. Karantino metu pavojus studentų sveikatai dèl sumažèjusio fizinio aktyvumo dar daugiau padidejo. Žmogaus kaulų ir raumenų sistema nèra pritaikyta ilgai trunkančiam darbui sédimoje padetyje. Pakankamas fizinis aktyvumas, pasyvios ir aktyvios veiklos kaita padètų atramos ir judèjimo organų sistemai išlikti sveikai.

C. Romero-Blanco ir kt. (2020) rekomendavo dèti daugiau pastangų kuriant strategijas, kurios motyvuotų studentus sveikai gyventi, skatintų fizinį aktyvumą ir trumpintų sèdèjimo laiką [15]. Daugiau dèmesio reikètų skirti sveikatą stiprinančiam fiziniam aktyvumui, sudarant saugią ir patrauklią aplinką [6]. Fiziniai pratimai ir fizinè veikla ịgalintų stiprinti visuomenès fizinę ir psichikos sveikatą, padètų išvengti streso ir susirgimų.

\section{Išvados}

1. Tyrimas atskleide, kad pandemijos metu dauguma studentų prie kompiuterio praleido daug valandų per dieną ir tik mažuma darè reguliarias pertraukas. Tiriamieji minèjo nepakankamai tinkamą darbo įrangą ir darbo aplinką, dauguma jaute įvairių kūno vietų skausmus. Dauguma studentų nurodè, kad deda per mažai pastangų fiziniam aktyvumui ir fizinei veiklai didinti. Dauguma noretų mankštintis su bendraamžiais ir draugais, bet tai yra sudetinga karantino metu.

2. Tyrimo rezultatai parodė studentų sveikos gyvensenos ugdymo, saugios ir sveikos darbo kompiuteriu aplinkos kūrimo ir fizinio aktyvumo skatinimo poreikį.

3. Studentų informavimas apie fizinio aktyvumo poveikị sveikatai, jų motyvavimas būti fiziškai aktyvesnius ir patrauklesnès bei prieinamesnès fizinès veiklos organizavimas yra svarbūs veiksniai studentų sveikatai stiprinti.

\section{Literatūra}

1. Dunstan DW, Barr ELM, Healy GN, Salmon, J, Shaw JE, Balkau B, Magliano DJ, Cameron AJ, Zimmet PZ, Owen $\mathrm{N}$. Television viewing time and mortality: The Australian diabetes, obesity and lifestyle study (AusDiab). Circulation 2010,121(3):384-391.

https://doi.org/10.1161/CIRCULATIONAHA.109.894824

2. Kwan MY, Cairney J, Faulkner GE, Pullenavegum EE. Physical activity and other health-risk behaviours during the transition into adulthood: A longitudinal cohort study, American Journal of Preventive Medicine 2012;42(1):14-20.

https://doi.org/10.1016/j.amepre.2011.08.026

3. Winkler EA, Chastin S, Eakin E, Owen N, Lamontagne A, Moodie M, Dempsey P, Kingwell B, Dunstan D, Healy G. Cardiometabolic impact of changing sitting, standing, and stepping in the workplace. Medicine Science Sports Exercise 2018;50(3):516-524.

https://doi.org/10.1249/MSS.0000000000001453

4. Lee SP, Hsu YT, Bair B, Toberman M, Chien LC. Gender and posture are significant risk factors to musculoskeletal symptoms during touchscreen tablet computer use. Journal of Physical Therapy Science 2018;30(6):855-861. https://doi.org/10.1589/jpts.30.855

5. Physical activity and the risk of cancer. World Cancer Research Fund/American Institute for Cancer Research. Continuous Update Project Expert Report 2018. https://www.wcrf.org/ sites/default/files/Physical-activity.pdf

6. Strukčinskienė B., Raistenskis J., Radžiuvienė R., Strukčinskaitė V. Vaikų ir paauglių sveikos gyvensenos veiksniai: fizinio aktyvumo ypatumai. Spaustuvė Druka (Klaipeda), 2018.

7. Adaškevičienė E., Strazdienė N. Mokinių fizinio aktyvumo edukacija. Monografija. KU leidykla (Klaipėda), 2017. 
8. Becker DR, McClelland MM, Loprinzi P, Trost SG. Physical activity, self-regulation, and early academic achievement in preschool children. Early Education and Development 2014,25:56-70.

https://doi.org/10.1080/10409289.2013.780505

9. Kahan D, Nicaise V, Reuben K. Effects of a bug-in-the-ear intervention to increase physical activity prompting and level during preschool recess. The Physical Educator 2016;73:555-577. https://doi.org/10.18666/TPE-2016-V73-I3-6415

10. Bélanger M, Humbert L, Vatanparast H, Ward S, Muhajarine N, Chow AF, Engler-Stringer R, Donovan D, Carrier N, Leis A. A multilevel intervention to increase physical activity and improve healthy eating and physical literacy among young children (ages 3-5) attending early childcare centres: The Healthy Start-Départ Santé cluster randomised controlled trial study protocol. BMC Public Health 2016;16(313):1-10.

https://doi.org/10.1186/s12889-016-2973-5

11. Martinez-Lemos RI, Puig-Ribera AM, Garcia-Garcia O. Perceived barriers to physical activity and related factors in Spanish university students. Open Journal of Preventive Medicine 2014;4(4):164-174.

https://doi.org/10.4236/ojpm.2014.44022

12. Mohammed G, Said SM, Ariffin AA, Kamaruzaman J. Physical inactivity and its associated factors among university students. Journal of Dental and Medical Sciences 2014;13(10): 119-130. https://doi.org/10.9790/0853-13101119130

13. Fagaras S, Radu LE, Vanvu GI. The level of physical activity of university students. Social and Behavioral Sciences 2015;197:1454-1457.

https://doi.org/10.1016/j.sbspro.2015.07.094

14. Masarykova D, Labudova J, Matúš I. Physical activity of university students with various study profile. Physical Activity Review 2016;4:107-114. https://doi.org/10.16926/par.2016.04.13

15. Romero-Blanco C, Rodríguez-Almagro J, Onieva-Zafra MD, Parra-Fernández ML, Prado-Laguna MC, Hernández-Martínez A. Physical activity and sedentary lifestyle in university students: Changes during confinement due to the COVID-19 pandemic. International Journal of Environmental Research and Public Health 2020;17(18):6567.

https://doi.org/10.3390/ijerph17186567

16. Gallo LA, Gallo TF, Young SL, Moritz KM, Akison LK. The impact of isolation measures due to COVID-19 on energy intake and physical activity levels in Australian university students. Nutrients 2020;12(6):1865.

https://doi.org/10.3390/nu12061865

17. Wang Y, Szeto GPI, Chan CCH. Effects of physical and mental task demands on cervical and upper limb muscle activity and physiological responses during computer tasks and recovery periods. Euopean Journal of Applied Physiology 2011; 111(11):2791-2803.

https://doi.org/10.1007/s00421-011-1908-1

18. Lipošek S, Planinšec J, Leskošek B, Pajtler A. Physical activity of university students and its relation to physical fitness and academic success. Annales Kinenesiologiae 2018;9(2): 89-104. https://doi.org/10.35469/ak.2018.171

\section{UNIVERSITY STUDENTS‘ LIFESTYLE DURING PANDEMIC: FOCUS ON COMPUTER-BASED WORK AND PHYSICAL ACTIVITY \\ V. Strukčinskaitė, B. Strukčinskienė, N. Strazdienė, S. Griškonis}

Keywords: university students, lifestyle, pandemic, computer, work, physical activity.

Summary

During the COVID-19 pandemic, the transition to distance learning changed the study environment and the nature of activities of university students, heading to the increase of the computer-based workload. The physical inactivity and the duration of sedentary time in young people increased over this period. The aim of the study was to study the lifestyle of university students, the environment of the work with the computer, and the aspects of physical activity during pandemic. The survey was conducted in Lithuanian universities in 2020, after the first wave of a pandemic, and 201 student (48.8\% male and 51.2\%) took part in it. Chi-Square test used in the study.

The survey showed that a half of students use computer 6-10 hours per day, and $12 \%$ - over 10 hours per day. Most young people used unsuitable chair, insufficient computer table area, and insufficient working space. $22.9 \%$ of students had a very good, $55.2 \%-$ good, and $21.4 \%$ - a moderate illumination. During work with the computer, other people distracted $40.8 \%$ of students, and $21.4 \%$ students were disturbed by noise. Over half of young people had pain in the neck, shoulders, and back area. $10.9 \%$ of students selfrated their physical health as very good, $49.3 \%$ - as good. $32.8 \%$ of students have enough knowledge on physical activities' impact to health. $11.9 \%$ students were exercising or used sport training at least 30 minutes daily, and $24.9 \%$ - exercised at least 30 minutes 2-3 times per week. $62.2 \%$ of young people agreed that they need more activities that are physical. $38 \%$ of students had regular breaks during work with the computer. $68 \%$ of students prefer to exercise with peers and friends, $19 \%$ - with family members.

Conclusions. During the pandemic, most young people spent too many hours per day while working at a computer, and only a minority of students took regular breaks. The young people surveyed mentioned inconvenient working equipment and working environment, and most of them suffered from pain in various parts of the body. Most students indicated that they put too little effort for increasing physical activity. Most students like to exercise with peers and friends. Thus, the development of a healthy lifestyle of students, the creation of a safe and healthy computer-based environment, and the promotion of physical activity need more attention. Informing students about the effects of physical activity on health, motivating them to be more physically active and organizing more attractive and accessible physical activities are important factors in students' health promotion.

Correspondence to: vaiva.struk@gmail.com

Gauta 2021-09-28 